\title{
La sous-alimentation énergétique et/ou azotée chez la vache tarie. Effets sur les acides gras volatils du rumen, quelques métabolites et hormones du plasma et l'excrétion urinaire de la 3-méthylhistidine
}

\author{
BB Ndibualonji 1, D Dehareng 2, JM Godeau 1 \\ 1 Laboratoire de biochimie, faculté de médecine vétérinaire, université de Liège, \\ bd de Colonster, 20, B42, B-4000 Liège-Sart Tilman, Belgique; \\ 2 Département des productions animales, faculté des sciences agronomiques (FACAGRO), \\ université du Burundi, BP 2940, Bujumbura, Burundi
}

(Reçu le 21 mars 1994 ; accepté le 10 janvier 1995)

\begin{abstract}
Résumé - Dans le but d'étudier les effets d'une sous-alimentation azotée et/ou énergétique sur certains métabolites et hormones, 4 vaches taries ont été nourries en 2 repas journaliers égaux avec des régimes à base de foin. Quatre rations ont été distribuées : elles apportaient trop (HN) ou trop peu (LN) de protéines digestibles dans l'intestin et trop (HE) ou trop peu (LE) d'énergie nette, soit les régimes HN-HE, HN-LE, LN-HE et LN-LE. Des prélèvements continus de liquide ruminal (dosages des acides gras volatils ou AGV), de sang veineux (dosages des acides aminés [alanine ou Ala, glutamine ou Gln, glycine ou Gly et sérine ou Ser], de l'urée, de glucose, de l'insuline et de l'hormone de croissance $(\mathrm{GH})$ ) et d'urine (détermination de la quantité de la 3-méthylhistidine ou 3-MeHi excrétée) ont été réalisés pendant une période de $24 \mathrm{~h}$ consécutives. Quel qu'ait été le type de sous-alimentation, et par comparaison avec le régime de référence (HN-HE), nous avons observé une diminution des teneurs en AGV totaux du rumen, un relèvement de celles de la Gly et de la GH du plasma, et un maintien des valeurs de la glycémie. En outre, la sous-alimentation azotée et énergétique (LN-LE) s'est accompagnée d'une réduction des concentrations plasmatiques en Ala, Gln et insuline ; la sous-alimentation azotée ( $\mathrm{LN}-\mathrm{HE})$, d'une réduction des valeurs de l'urémie, d'un accroissement de celles de la sérinémie et d'un maintien de l'insulinémie ; la sous-alimentation énergétique (HN-LE), d'une réduction des concentrations plasmatiques en insuline et d'un relèvement de celles de l'Ala et de la Ser. Ces modifications suggèrent que la vache tarie s'adapte à la sous-alimentation en mobilisant ses réserves protéiques. Cependant, seuls les 2 régimes déficitaires en apports énergétiques ont été accompagnés d'une élévation $(P<0,05)$ de la quantité de la 3-MeHi urinaire excrétée par $24 \mathrm{~h}$, suggérant que le niveau énergétique de la ration est le facteur déterminant de la mobilisation protéique. Enfin, l'étude de l'évolution cinétique des paramètres a révélé une influence du moment du repas (matin ou soir) et du niveau des apports azotés et énergétiques de la ration sur la variation de leur concentration.
\end{abstract}


Summary - Nitrogenous and/or energetic underfeeding in the dry cow. Effects on ruminal volatile fatty acids, some plasma metabolites and hormones, and urinary excretion of 3-methylhistidine. In order to study the effects of a nitrogenous and/or energetic underfeeding on some metabolites and hormones, $4 d y$ cows were fed in 2 equal daily meals with hay-based rations. Four rations were distributed. They supplied too much $(H N)$ or too little $(L N)$ digestible protein in the small intestine and too much (HE) or too little (LE) net energy, ie the diets were HN-HE, HN-LE, LN-HE, and LN-LE. Continuous collection of rumen liquor samples (volatile fatty acids or VFA determination), venous blood samples (amino acids (alanine Ala, glutamine Gln, glycine Gly and serine Ser), urea, glucose, insulin and growth hormone (GH) measurements) and urine samples (determination of the amount of 3-methylhistidine 3-MeHi excreted) was carried out for 24 consecutive hours. By comparison with the reference diet (HN-HE), underfeeding was accompanied by a reduction in ruminal VFA concentrations, an increase in those of plasma Gly and $\mathrm{GH}$, and a maintenance of glycemia levels. Furthermore, nitrogenous and energetic underfeeding ( $L N-L E)$ was accompanied by a decrease in plasma Ala, Gin and insulin concentrations. Nitrogenous underfeeding ( $L N-H E)$ caused a decrease in uremia levels, an increment in those of serinemia and no variation in circulating insulin concentrations. The energetic underfeeding ( $H N-L E$ ) was accompanied by a reduction in insulinemia levels and an increase in those of alaninemia and serinemia. Such changes suggest that dry cattle adapt to underfeeding by mobilizing endogenous proteins. However, only the 2 diets with reduced energetic supplies were accompanied by an increase $(\mathrm{P}<0.05)$ in the amount of the urinary 3-MeHi excreted per $24 \mathrm{~h}$, suggesting that the level of energy in the diet is the main trigger for protein mobilization. Finally, the study of the 24- $h$ evolution of the parameters revealed the influence of the feeding time (morning or evening) and the level of the dietary nitrogen and energy supplied on the variation in their concentration.

\section{nitrogen / energy / metabolite / hormone / cattle}

\section{INTRODUCTION}

Il est bien établi chez le Ruminant qu'en raison de la fermentation microbienne des glucides alimentaires dans le rumen très peu de glucose exogène est disponible pour son absorption intestinale : chez la vache alimentée avec des régimes usuels, 10 à $15 \%$ seulement des besoins journaliers en glucose sont couverts par l'alimentation tandis que le reste (85-90\%) proviendrait de la néoglucogenèse (Otchere et al, 1974).

Lorsque l'animal est normalement nourri, c'est le propionate produit dans le rumen qui est le principal substrat glucoformateur (Lomax et Baird, 1983). En revanche, dans des situations de jeûne ou de restriction alimentaire où l'apport de propionate devient limitant, ce sont surtout les acides aminés (AA), le lactate et le glycérol qui fournissent les chaînes carbonées nécessaires à la synthèse du glucose (Ndibualonji et Godeau, 1993). Ces adaptations métaboliques sont favorisées par un nouvel équilibre endocri- nien, caractérisé notamment par une diminution des concentrations circulantes en insuline et une élévation de celles de la $\mathrm{GH}$ (Kunz et al, 1985 ; Bocquier et al, 1992 ; Ndibualonji et Godeau, 1992). Dans toutes ces études, une remarquable homéostasie de la glycémie a été observée.

Cependant, d'une part, il n'existe, à notre connaissance, aucune étude relative à une influence simultanée de 2 niveaux énergétiques et 2 niveaux azotés sur les concentrations moyennes des métabolites et des hormones chez la vache tarie. D'autre part, les échantillons de sang destinés au dosage des métabolites et des hormones dans les études précédentes ont souvent été prélevés de manière ponctuelle et pendant des périodes limitées (souvent diurnes) de la journée.

De plus, si certains chercheurs (Hove et Blom, 1973 ; Blum et al, 1985 ; Clement et al, 1991) ont étudié l'évolution nycthémérale des métabolites et des hormones du plasma chez la vache, cette évolution n'est 
toujours pas connue pour l'excrétion urinaire de la 3-MeHi.

C'est dans le but de combler ces lacunes que la présente étude a été entreprise. Effectuée chez la vache tarie, elle vise à étudier l'impact d'une restriction énergétique et/ou azotée de la ration sur les niveaux moyens et sur l'évolution nycthémérale de certains métabolites (AGV du rumen ; AA, glucose et urée du plasma ; 3-MeHi urinaire) et hormones (insuline et GH du plasma) lorsque les échantillons de sang sont prélevés en continu pendant une période de $24 \mathrm{~h}$ consécutives.

\section{MATÉRIEL ET MÉTHODES}

Réparties selon un dispositif expérimental en carré latin, 4 vaches Frisonnes âgées de $47 \pm 6$ mois, pesant $516 \pm 18 \mathrm{~kg}$, taries, non gravides et porteuses de 2 canules permanentes (rumen, duodénum) ont reçu 2 repas journaliers égaux (6 15-15 $30 \mathrm{~h}$ ) d'un régime à base de foin.

Des rations apportant, par rapport aux besoins théoriques des animaux, soit trop peu de protéines digestibles dans l'intestin (PDI) et d'énergie nette (régime LN-LE), soit trop de PDI et trop peu d'énergie nette (régime HN-LE) ou l'inverse (régime LN-HE) ont été comparées à une ration excédentaire (HN-HE ; tableau I). Les apports de PDI ont été estimés à partir des tables ali-

Tableau I. Composition moyenne des rations.

\begin{tabular}{|c|c|c|c|c|}
\hline Régimes * & $L N-L E$ & $L N-H E$ & $H N-L E$ & $H N-H E$ \\
\hline \multicolumn{5}{|l|}{ Ingestion en produit brut $(\mathrm{kg} / \mathrm{j})$ : } \\
\hline Foin de prairie & $1,8^{a}$ & $2,0^{a}$ & $1,8^{a}$ & $3,0^{\mathrm{b}}$ \\
\hline Pulpes sèches & $2,0^{\mathrm{a}}$ & - & - & $2,5^{\mathrm{b}}$ \\
\hline Concentré $12^{* *}$ & $0,9^{\mathrm{a}}$ & - & - & $1,8^{b}$ \\
\hline Concentré $18^{* *}$ & - & - & 2,8 & - \\
\hline Concentré $E^{\star \star *}$ & - & 5,0 & - & - \\
\hline \multicolumn{5}{|l|}{ Composition chimique } \\
\hline Matière sèche $(\mathrm{kg} / \mathrm{j})$ & $4,2^{\mathrm{a}}$ & $6,1^{b}$ & $4,1^{a}$ & $6,4^{b}$ \\
\hline Matière organique $(\mathrm{kg} / \mathrm{j})$ & $3,9^{a}$ & $5,6^{b}$ & $3,9^{a}$ & $6,0^{\circ}$ \\
\hline Azote total $(\mathrm{g} / \mathrm{j})$ & $77,3^{\mathrm{a}}$ & $85,1^{b}$ & $106,0^{c}$ & $122,6^{d}$ \\
\hline Protéines brutes (\%/MS) & $11,5^{a}$ & $8,8^{b}$ & $16,1^{\mathrm{c}}$ & $12,0^{\mathrm{d}}$ \\
\hline Énergie brute $(\mathrm{MJ} / \mathrm{j})$ & $93,5^{\mathrm{a}}$ & $121,6^{b}$ & $89,5^{a}$ & $142,3^{c}$ \\
\hline Pourcentage de foin & $39,1^{a}$ & $30,2^{b}$ & $39,9^{\mathrm{ac}}$ & $41,9^{c}$ \\
\hline Pourcentage de concentré & $19,1^{\mathrm{a}}$ & $71,4^{b}$ & $60,9^{\mathrm{c}}$ & $24,7^{d}$ \\
\hline \multicolumn{5}{|l|}{ Apports ${ }^{\star \star \star \star}$} \\
\hline Énergie nette (UFL/j) & 3,6 & 5,3 & 3,5 & 5,4 \\
\hline (\% des besoins) & 80 & 119 & 74 & 122 \\
\hline PDI $(g / j)$ & 297 & 300 & 459 & 476 \\
\hline (\% des besoins) & 84 & 85 & 131 & 137 \\
\hline PDIN $(g / j)$ & 297 & 300 & 460 & 476 \\
\hline $\operatorname{PDIE}(g / j)$ & 399 & 520 & 459 & 617 \\
\hline
\end{tabular}

* $L$ : niveau faible $; \mathrm{H}$ : niveau important $; \mathrm{N}$ : azote alimentaire ; $\mathrm{E}$ : énergie alimentaire. ${ }^{* *}$ Aliments concentrés du commerce (Moulins Dedobbeleer, Halle-Belgique) à 12 et $18 \%$ de protéines brutes. ${ }^{\star \star \star}$ Aliment composé de $60 \%$ de pulpes de betteraves, $20 \%$ d'amidon de maïs et $20 \%$ de paille d'orge. ${ }^{\star \star \star \star}$ Non analysés statistiquement. a, b, $c, d$ Les moyennes dans la même ligne qui n'ont pas une lettre commune en indice sont différentes statistiquement $(P<0,05)$. 
mentaires (Andrieu et al, 1988) et la valeur énergétique nette des régimes par récolte totale des excreta pendant les 5 j qui précédaient le début de la récolte des liquides biologiques (Dehareng et Godeau, 1991) (tableau II). Une période d'adaptation alimentaire de 3 sem a précédé le début du prélèvement des excreta, et les animaux disposaient en permanence d'eau de boisson et de pierres à lécher.

Hormis le régime $H N$-LE, les rations étaient déficitaires en azote dégradable dans le rumen, ce qui devait théoriquement favoriser un recyclage de l'azote endogène dans le tractus digestif (PDIE > PDIN ; Vérité et Peyraud, 1988 ; tableau I). Afin de s'en assurer, les flux duodénaux d'azote total ont été évalués selon la méthodologie du double marquage (phase solide : oxyde de chrome, $20 \mathrm{~g} / \mathrm{j}$; phase liquide : polyéthylèneglycol [PM : 4000] $90 \mathrm{~g} / \mathrm{j}]$ associée à des prélèvements de chyme duodénal. La distribution de ces marqueurs a débuté $5 \mathrm{j}$ avant la période de prélèvement de chyme duodénal afin que la concentration d'équilibre ("steady-state») de chaque marqueur soit bien établie. En période de prélèvement, $200 \mathrm{~g}$ de digesta duodénaux ont été collectés, de $2 \mathrm{~h}$ en $2 \mathrm{~h}$, par la canule duodénale de chaque animal. Ces prélèvements ont débuté le lendemain du terme de la collecte des excreta et ont été répartis sur 3 périodes successives chevauchant 2 j consécutifs : de 7 à $13 \mathrm{~h}$ le premier jour, de 23 à $5 \mathrm{~h}$ et de 15 à $21 \mathrm{~h}$ le deuxième jour. Ce procédé a permis de couvrir une période complète de $24 \mathrm{~h}$.

À l'issue de la période des prélèvements du chyme duodénal, des prélèvements continus de liquide ruminal, de sang veineux et d'urine ont été réalisés pendant une période de $24 \mathrm{~h}$ consécutives, le premier prélèvement débutant à $14 \mathrm{~h}$.

Les prélèvements de liquide du rumen (dosage des AGV) étaient réalisés à l'aide d'une sonde perforée immergée dans le liquide du sac ventral. Deux cathéters émergaient de cette sonde, et franchissant un orifice prévu à cet effet dans le corps de la canule ruminale, étaient connectés - hors du corps de l'animal - à un robinet à 3 voies. Celui-ci était, à son tour, relié à une pompe péristaltique (Technicon Auto-Analyser Proportioning pump I, Dublin). Cette pompe prélevait en permanence $5,1 \mathrm{ml} / \mathrm{min}$ de liquide dont $2 \mathrm{ml} / \mathrm{min}$ étaient dirigés en continu vers un collecteur de fractions (20 min/fraction) placé dans une chambre froide $\left(4^{\circ} \mathrm{C}\right)$ située à $1,50 \mathrm{~m}$ des animaux, l'éxcédent du liquide étant restitué à tout moment à l'animal par un troisième cathéter dont l'extrémité débouchait juste derrière le bouchon de la canule qu'il traversait.

Le prélèvement sanguin en continu était effectué selon une variante de la méthode de Ladewig et Stribrny (1988). La veille du jour où le prélèvement sanguin devait être effectué, un introducteur (Désilet 1129-07 ; Vygon, 95440 Écouen, France) était implanté, sous anesthésie locale, dans une veine jugulaire de l'animal. Le jour de la collecte de sang et après avoir prélevé à la seringue un peu de sang veineux complet, une extrémité d'un cathéter à double lumière (Clear vinyl tube 190290-DV12, Dural Plastics, Auburn, Australie) était insérée, via l'introducteur, dans la veine jugulaire tandis que l'autre extrémité du cathéter était connectée à une pompe péristaltique (Technicon Auto-Analyser Proportioning pump I, Dublin). Une solution de liquide physiologique et hépariné $(50 \mathrm{Ul} / \mathrm{ml})$ était infusée en permanence $(0,1 \mathrm{ml} / \mathrm{min})$ par l'une des voies du cathéter tandis que du sang hépariné était continuellement prélevé $(0,42 \mathrm{ml} / \mathrm{min})$ par la seconde voie du cathéter, celle-ci s'ouvrant à côté de la première. Le sang prélevé était dirigé en continu vers un collecteur de fractions ( 1 fraction/10 $\mathrm{min}$ ) placé dans une chambre froide $\left(4^{\circ} \mathrm{C}\right)$. Après centrifugation ( $1500 \mathrm{~g} ; 20 \mathrm{~min})$, le plasma résiduel

Tableau II. Valeurs énergétiques et azotées des constituants de la ration.

\begin{tabular}{lccccc} 
& Foin & Pulpes & C12 & C18 & CE \\
\hline \% MS/kg frais & 91,17 & 87,72 & 87,06 & 87,82 & 86,59 \\
g MAD/kg frais & 50 & 50 & 110 & 128 & 40 \\
UFL $/ \mathrm{kg}$ frais & 0,54 & 0,85 & 0,87 & 0,87 & 0,79 \\
& & & & & \\
\hline
\end{tabular}

$C$ : Concentré ; MS : matière sèche ; MAD : matières azotées digestibles. 
contenu dans chaque fraction était aliquoté, le plasma de 2 (dosages de l'urée, l'insuline et la $\mathrm{GH}$ ) ou de 6 (dosages des AA et du glucose) fractions successives étant rassemblé pour constituer des échantillons plasmatiques couvrant des périodes de 20 ou $60 \mathrm{~min}$ consécutives. Après avoir déprotéinisé une partie du plasma (dosage des AA uniquement) avec l'acide trichloracétique à $5 \%(\mathrm{vol} / \mathrm{vol})$, tous les échantillons de plasma étaient congelés $\left(-20^{\circ} \mathrm{C}\right)$ jusqu'au moment des analyses. Au terme du prélèvement sanguin en continu, le cathéter à double lumière était enlevé et un dernier échantillon de sang veineux complet était prélevé à la seringue. La mesure de l'hématocrite du sang complet prélevé avant et après le prélèvement en continu ainsi que la mesure de l'hématocrite des échantillons de sang hépariné et prélevé en continu permettaient de calculer le facteur de dilution du sang par la solution héparinée et, partant, de connaître la teneur plasmatique réelle en métabolites et en hormones.

Les échantillons d'urine ont été collectés en continu ( $2 \mathrm{~h} /$ fraction ; détermination de la quantité de la 3-MeHi excrétée) par l'intermédiaire d'une sonde à ballonnet en silkolatex (Rüsch-Gold, $n^{\circ} 18-06-30$ ) placée $6 \mathrm{~h}$ avant le début des prélèvements dans la vessie, en passant par l'urètre. Un tuyau en plastique souple reliait l'extrémité de la sonde à un récipient collecteur. Au terme de chaque période de $2 \mathrm{~h}$ de récolte, le volume total d'urine émise était enregistré et, après homogénéisation, une fraction $(10 \mathrm{ml})$ était prélevée puis centrifugée $(1500 \mathrm{~g} ; 10 \mathrm{~min})$. Le surnageant était acidifié ( $1 \% \mathrm{vol} / \mathrm{vol}$ par une solution d' $\mathrm{HCl}$ $10 \mathrm{M}$ ) avant d'être conservé à $-20^{\circ} \mathrm{C}$ jusqu'au moment des analyses.

Pendant toute la durée des prélèvements en continu, les durées d'ingestion des repas étaient enregistrées selon Dehareng et Godeau (1991). Ces mesures étaient uniquement destinées à alimenter la discussion des évolutions nycthémérales des métabolites et des hormones.

La teneur en matière sèche des aliments, des matières fécales et du contenu duodénal a été déterminée par dessication à l'étuve $\left(105^{\circ} \mathrm{C}\right)$ jusqu'à obtenir la constance du poids.

La teneur en matière organique des aliments a été déterminée par le calcul de la différence entre le pourcentage de matière sèche et celui des matières minérales totales (cendres). Ce dernier a été mesuré par la disparition de matière lors d'une incinération directe au four à moufle $\left(550^{\circ} \mathrm{C}\right)$ pendant $12 \mathrm{~h}$.
La mesure de l'azote total contenu dans les aliments (mesure sur matière fraîche) et dans le chyme duodénal a été effectuée selon la méthode de Kjeldahl adaptée au dosage de routine sur un Auto-Analyzer Technicon. Le dosage des AGV a été réalisé par chromatographie en phase gazeuse avec un détecteur à ionisation de flamme (Van Eenaeme et al, 1965). L'urémie a été déterminée selon une méthode à la thiosemicarbazide adaptée au dosage de routine sur un AutoAnalyzer Technicon. Les concentrations des AA plasmatiques et de la 3-MeHi urinaire ont été déterminées par chromatographie liquide à haute performance (HPLC ; Ndibualonji et al, 1992). La mesure du glucose a été effectuée par une méthode colorimétrique à l'hexokinase (Schmidt, 1961). Les teneurs plasmatiques en insuline et en GH ont été déterminées par dosage radioimmunologique (Ndibualonji et Godeau, 1992).

Les variations (nombre de pics, amplitude des pics, intervalle entre les pics et surface sous les pics) dans les profils journaliers de GH plasmatique ont été analysées à l'aide du programme informatique mis au point par Taylor (1987).

L'analyse statistique a d'abord consisté en une analyse de la variance pour un schéma en carré latin (Cox, 1958). Ensuite, en cas d'effet statistique des régimes étudiés, les différences entre les moyennes ont été déterminées à l'aide d'une classification en rangs multiples (Duncan, 1955).

\section{RÉSULTATS}

\section{Durée et vitesse d'ingestion des repas}

Par comparaison avec le régime HN-HE, la diminution des apports azotés et/ou énergétiques de la ration s'est accompagnée d'une diminution $(P<0,05)$ de la durée d'ingestion du repas du soir et, hormis HN-LE, d'une augmentation $(P<0,05)$ de la vitesse d'ingestion de ce repas (tableau III). À l'opposé, la réduction des apports azotés et/ou énergétiques n'a pas eu d'influence sur les paramètres d'ingestion du repas du matin, hormis la diminution nette de la durée d'ingestion enregistrée avec le régime HN-LE (vs HN-HE ; tableau III). 
Tableau III. Durée et vitesse d'ingestion des repas.

\begin{tabular}{|c|c|c|c|c|c|}
\hline Régimes & $L N-L E$ & $L N-H E$ & $H N-L E$ & $H N-H E$ & $E T M^{*}$ \\
\hline \multicolumn{6}{|l|}{ Durée d'ingestion (min) } \\
\hline Repas du soir (à 15 h 30) & $37,0^{a}$ & $47,8^{a}$ & $60,6^{b}$ & $78,6^{c}$ & 3,2 \\
\hline Repas du matin (à 6 h 15) & $44,0^{\mathrm{ab}}$ & $45,6^{\mathrm{ab}}$ & $37,1^{1^{\star \star \star}}$ & $56,2^{b \star \star \star}$ & 4,4 \\
\hline \multicolumn{6}{|l|}{ Vitesse d'ingestion ${ }^{\star \star}(\mathrm{g} / \mathrm{min})$} \\
\hline Repas du soir (à 15 h 30) & $57,3^{a}$ & $65,8^{a}$ & $34,6^{b}$ & $41,3^{b}$ & 3,3 \\
\hline Repas du matin (à 6 h 15 ) & 51,6 & 67,6 & $57,6^{\star \star \star}$ & $58,7^{\star \star \star}$ & 6,4 \\
\hline
\end{tabular}

*Écart type de la moyenne ; ${ }^{\star \star}$ quantité de matière sèche ingérée par unité de temps; a, b, c les moyennes dans la même ligne qui n'ont pas une lettre commune en indice sont différentes statistiquement $(P<0,05) ;{ }^{\star \star \star}$ dans la même colonne et pour le même paramètre (durée ou vitesse d'ingestion), significativement différent du repas du soir (analyse de la variance pour mesures répétées) $n=4$.

Par ailleurs, et par comparaison avec le repas du soir, le repas du matin s'est caractérisé par une diminution $(P<0,05)$ de la durée et un accroissement concomitant $(P<0,05)$ de la vitesse d'ingestion avec les 2 régimes excédentaires en azote (tableau III).

\section{Acides gras volatils du liquide du rumen}

Par comparaison avec le régime excédentaire (HN-HE), la sous-alimentation énergétique et/ou azotée s'est traduite par une diminution significative $(P<0,05)$ de la

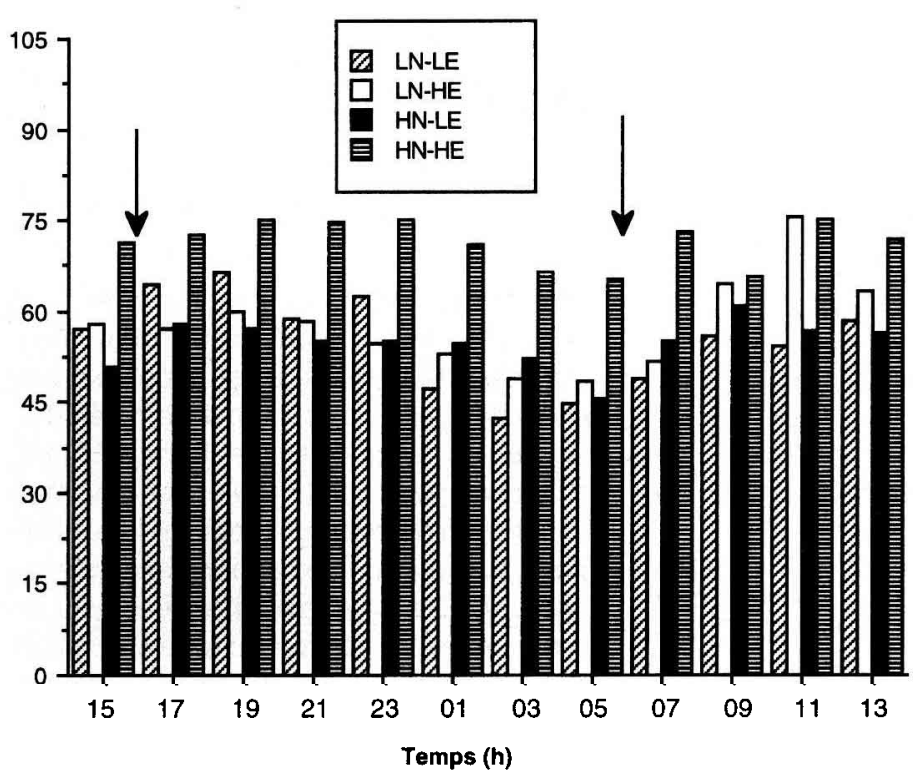

Fig 1. Évolution cinétique des acides gras volatils (méq/l) dans le rumen. Chaque rectangle représente la teneur moyenne enregistrée pendant $2 \mathrm{~h}$ de récolte continue et est centré sur le milieu de cette période. L : niveau faible; $\mathrm{H}$ : niveau important ; $\mathrm{N}$ : azote alimentaire ; $E$ : énergie alimentaire. Les flèches indiquent le moment des 2 distributions d'aliments (15 h $30-6$ h 15). 
concentration moyenne en AGV totaux (tableau IV).

Quant à l'évolution cinétique des AGV, et quel que soit le régime étudié, leur teneur ruminale présente un pic postprandial qui culmine entre 2 et $4 \mathrm{~h}$ après le repas. Cependant, le pic postprandial du soir se distingue de son homologue du matin, et surtout avec les régimes excédentaires en azote, par son long étalement (fig 1). Pour chaque régime, la teneur en AGV présente une nette tendance à décroître entre minuit et le début du repas du matin (fig 1).

\section{Caractéristiques du chyme duodénal}

Quel que soit le niveau azoté des régimes étudiés, un accroissement des apports éner- gétiques s'est traduit par une tendance à l'augmentation de la quantité d'azote atteignant le duodénum (tableau IV) et de l'apport endogène d'azote ( $N$ duodénal - $N$ ingéré) dans les préestomacs. En revanche et quel que soit le niveau énergétique des rations utilisées, un accroissement du taux azoté du régime tend à diminuer $(P<0,05)$ l'importance de l'apport endogène d'azote dans les préestomacs (tableau IV).

\section{Amino-acidémie libre}

Par comparaison avec le régime HN-HE, la sous-alimentation énergétique et azotée (LN-LE) s'est accompagnée d'une diminution $(P<0,05)$ des valeurs de l'alaninémie et de la glutaminémie, la sous-alimentation

Tableau IV. L'excrétion urinaire de la 3-méthylhistidine et les niveaux journaliers moyens des métabolites, des hormones et du flux duodénal d'azote total.

\begin{tabular}{|c|c|c|c|c|c|}
\hline Régimes & $L N-L E$ & $L N-H E$ & $H N-L E$ & $H N-H E$ & $E T M^{*}$ \\
\hline \multicolumn{6}{|l|}{ Rumen } \\
\hline AGV totaux (méq/l) & $55,0^{a}$ & $57,6 a$ & $54,7^{a}$ & $71,4^{b}$ & 3,4 \\
\hline \multicolumn{6}{|l|}{ Duodénum } \\
\hline Flux d'azote total $(\mathrm{g} / \mathrm{j})$ & 113,4 & 141,1 & 119,1 & 138,6 & 8,2 \\
\hline (en \% de $\mathrm{N}$ ingéré) & $146,7^{a}$ & $165,8^{\mathrm{a}}$ & $112,4^{b}$ & $113,5^{b}$ & 9,8 \\
\hline \multicolumn{6}{|l|}{ Plasma } \\
\hline Alanine $(\mu \mathrm{moles} / \mathrm{l})$ & $139 a$ & $158^{b}$ & $185^{\circ}$ & $171^{b}$ & 3,9 \\
\hline Glutamine ( $\mu$ moles $/ l)$ & $166^{a}$ & $183^{a b}$ & $185^{a b}$ & $197^{b}$ & 8,1 \\
\hline Glycine ( $\mu$ moles $/)$ & $226^{a}$ & $261^{b}$ & $243^{a b}$ & $186^{\circ}$ & 8,8 \\
\hline Sérine $(\mu$ moles $/ 1)$ & $74^{a}$ & $93^{b}$ & $109 b$ & $67^{a}$ & 6,7 \\
\hline Urée (mg/l) & $213^{a b}$ & $123^{a}$ & $300^{b}$ & $251^{b}$ & 28 \\
\hline Glucose $(\mathrm{mg} / 100 \mathrm{ml})$ & 79 & 78 & 87 & 90 & 4,0 \\
\hline Insuline $(\mu \mathrm{U} / \mathrm{ml})$ & $44^{a}$ & $51^{\mathrm{ab}}$ & $43^{a}$ & $55^{b}$ & 3,3 \\
\hline $\mathrm{GH}(\mathrm{ng} / \mathrm{ml})$ & $8,0^{a}$ & $8,5^{a}$ & $7,8^{a}$ & $6,4^{b}$ & 0,3 \\
\hline \multicolumn{6}{|l|}{ Urine } \\
\hline 3-méthylhistidine excrétée & & & & & \\
\hline$(\mu$ moles $/ 24 \mathrm{~h})$ & $3051 a$ & $1876 b$ & $3166 a$ & $1975 b$ & 228,9 \\
\hline
\end{tabular}

* Écart type de la moyenne; $a, b, c$ les moyennes dans la même ligne qui n'ont pas une lettre commune en indice sont différentes statistiquement $(P<0,05) ; n=4$. 
azotée (LN-HE) d'un accroissement des valeurs de la sérinémie et la sous-alimentation énergétique (HN-LE) d'une élévation des valeurs de l'alaninémie et de la sérinémie. En outre, et quel que soit le type de sous-alimentation, un accroissement des valeurs de la glycinémie a été observé (tableau IV).

Aucune évolution convergente n'a été observée dans les profils journaliers des AA. Cependant, dans la plupart des cas, une légère tendance à l'accroissement de leur concentration plasmatique a été observée 1 à $2 \mathrm{~h}$ après le repas. Ensuite, l'amino- acidémie décroît rapidement pour se maintenir à des niveaux bas pendant 3 à $6 \mathrm{~h}$ selon les régimes. Ces variations ont été plus marquées avec les 2 régimes à taux azoté élevé (fig 2). En particulier nous avons observé une diminution soutenue des valeurs de la glutaminémie avec le régime $L N-L E$ depuis la fin du repas du soir jusqu'à celui du matin, un accroissement soutenu des valeurs de l'alaninémie avec le régime $\mathrm{HN}-\mathrm{HE}$ entre $21 \mathrm{~h}$ et $4 \mathrm{~h}$ et une nette tendance à la diminution des valeurs de la glutaminémie, sérinémie et glycinémie avec le régime HN-LE entre minuit et $4 \mathrm{~h}$ environ (fig 2 ).
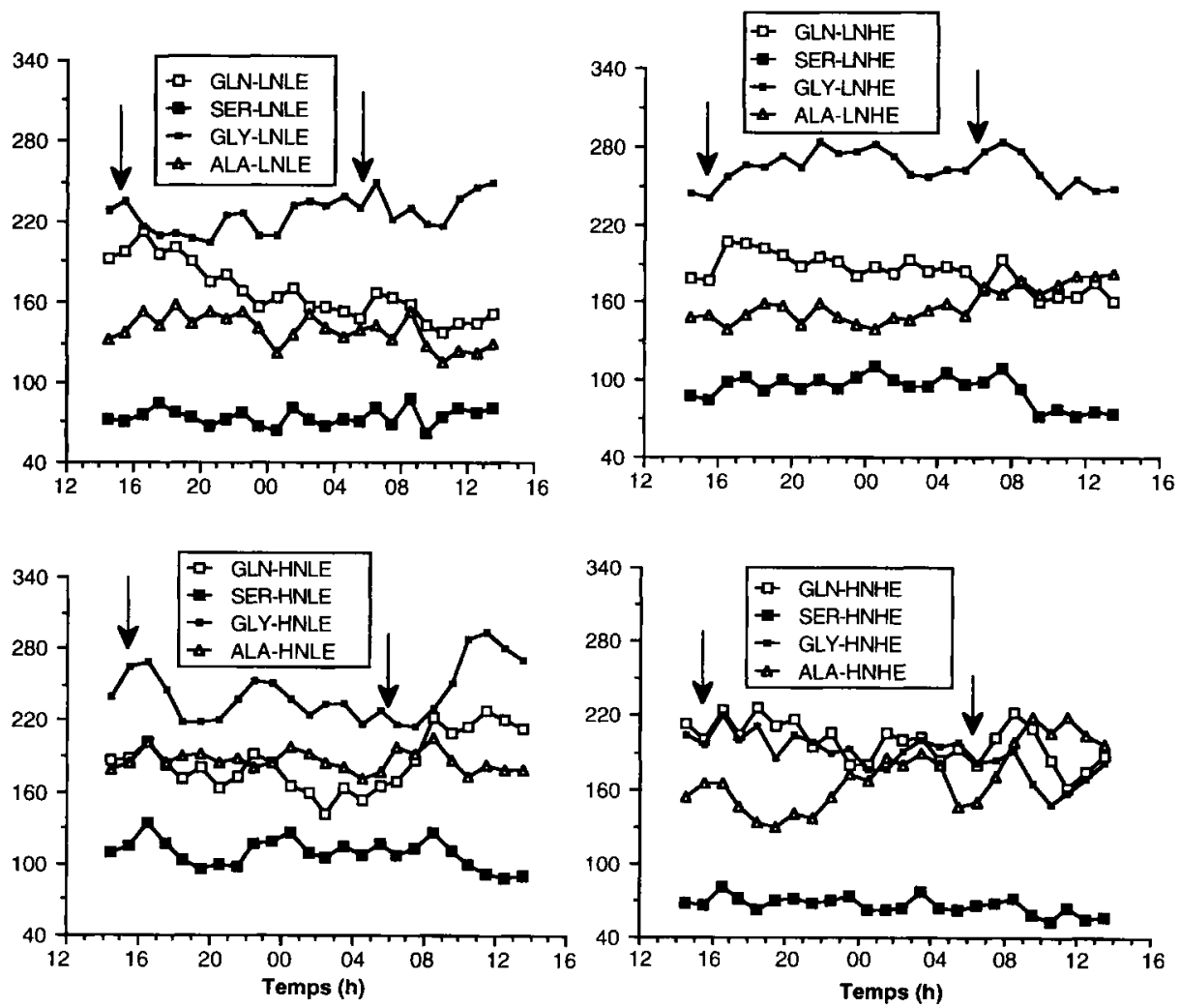

Fig 2. Évolution cinétique de l'amino-acidémie libre ( $\mu \mathrm{mol} / \mathrm{l})$. Chaque point représente la concentration moyenne calculée après $1 \mathrm{~h}$ de récolte continue et est centré sur le milieu de cette période. Les flèches indiquent le moment des 2 distributions d'aliments ( $15 \mathrm{~h} 30-6 \mathrm{~h} 15)$. 


\section{Urémie}

La sous-alimentation azotée (LN-HE vs HNLE et $\mathrm{HN}-\mathrm{HE}$ ) s'est traduite par une réduction $(P<0,05)$ des valeurs de l'urémie (tableau IV).

En ce qui concerne l'évolution nycthémérale de l'urée plasmatique, quel que soit le régime considéré, elle s'est caractérisée par l'absence de pic postprandial le soir alors que celui-ci est visible $2 \mathrm{~h}$ environ après le repas du matin (fig 3 ). Ensuite, un accroissement soutenu des valeurs de l'urémie a été observé entre minuit et $9 \mathrm{~h}$ environ (maximum journalier). Cette évolution a été particulièrement bien marquée pour les 2 régimes à faible concentration azotée (LNLE et LN-HE) (fig 3).

\section{Glycémie}

Aucune des rations étudiées n'a significativement affecté la teneur plasmatique en glucose. Toutefois, une diminution des apports azotés de la ration s'est accompagnée d'une tendance à l'abaissement des valeurs de la glycémie (tableau IV).

Quant à l'évolution cinétique de la glycémie, et à l'exception du régime $\mathrm{HN}-\mathrm{HE}$ (le soir), elle s'est caractérisée par une tendance à la diminution de la glycémie dans I'heure qui suit le repas (fig 4). Cependant, $2 \mathrm{~h}$ après le repas, on observe un accroissement des concentrations en glucose qui se maintient 4-5 $\mathrm{h}$ plus tard. Par ailleurs, une nouvelle tendance à l'accroissement est enregistrée entre minuit et $3 \mathrm{~h}$ (fig 4).

\section{Insulinémie}

La diminution des apports énergétiques de la ration s'est accompagnée d'une diminution $(P<0,05)$ subséquente des valeurs de l'insulinémie, ce qui n'a pas été observé lors de la sous-alimentation azotée (tableau IV). En outre, c'est le régime excédentaire (HN$\mathrm{HE}$ ) qui a donné lieu à la plus grande valeur de l'insulinémie.

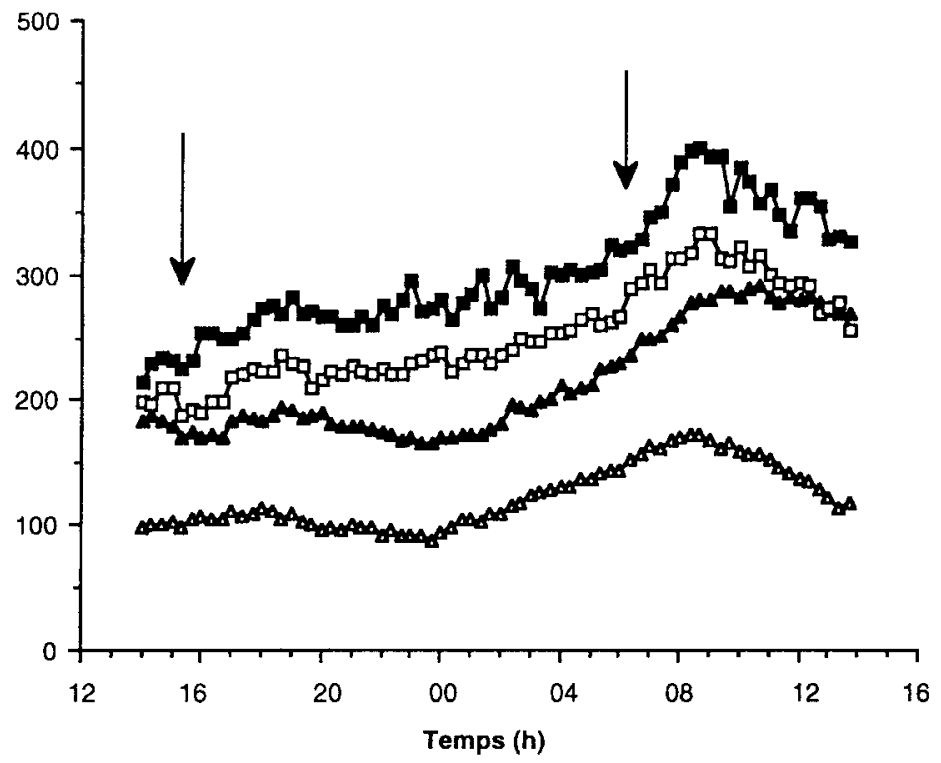

Fig 3. Évolution ciné-tique de l'urémie $(\mathrm{mg} / \mathrm{l})$. Les flèches indiquent le moment des 2 distributions d'aliments ( $15 \mathrm{~h} 30$ -6 h 15). - $A-:$ LNLE ; $-\Delta-:$ LN-HE ;
$-\square-H N-L E ;-\square-$ : HN-HE. 

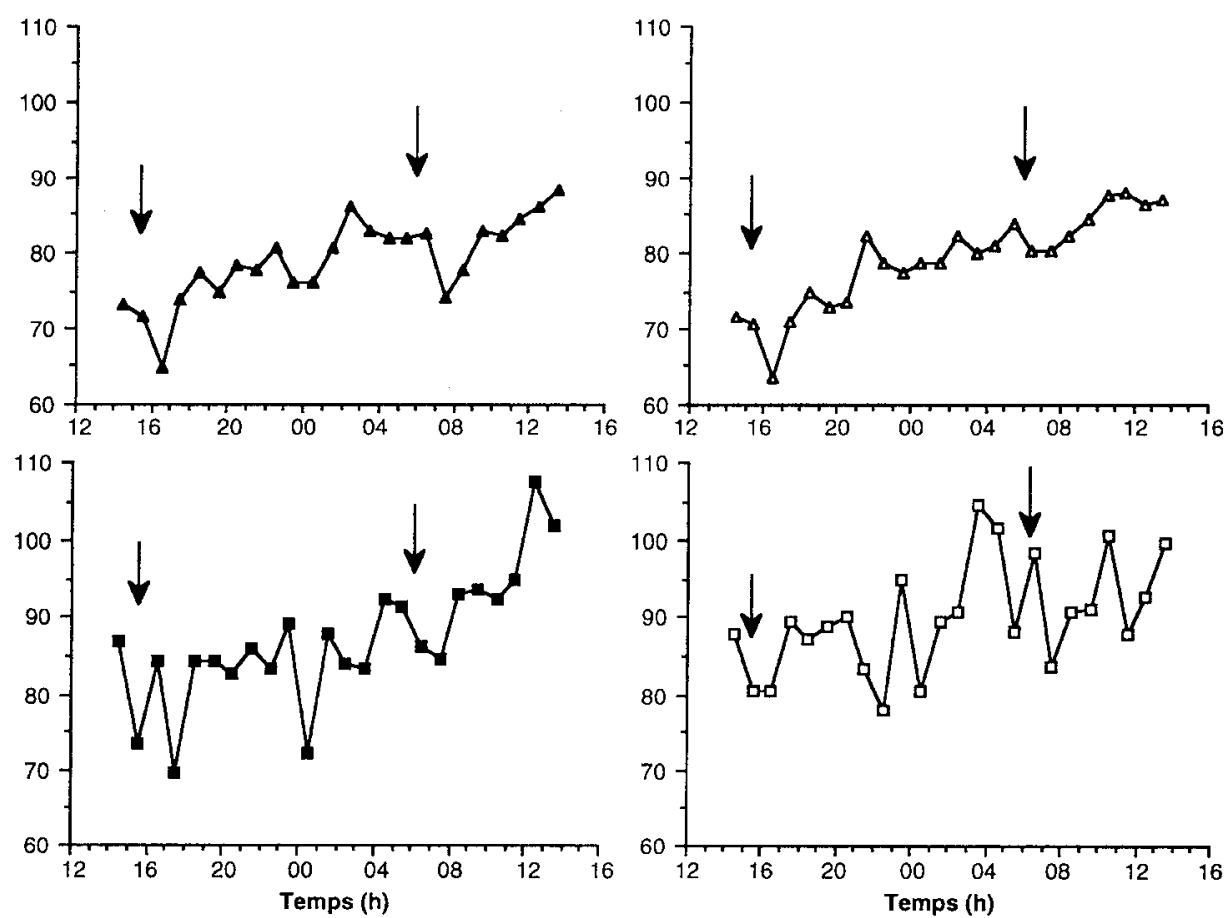

Fig 4. Évolution cinétique de la glycémie $(\mathrm{mg} / 100 \mathrm{ml})$. Chaque point représente la concentration moyenne calculée après $1 \mathrm{~h}$ de récolte continue et est centré sur le milieu de cette période. Les flèches indiquent le moment des 2 distributions d'aliments $(15 \mathrm{~h} 30-6 \mathrm{~h}$ 15). - $\mathbf{\Delta}$ : : LN-LE ; $-\Delta-:$ LN-HE ;

$-\square-\mathrm{HN}-\mathrm{LE} ; \multimap \square-\mathrm{HN}-\mathrm{HE}$.

Quant à l'évolution cinétique de l'insulinémie, et quel que soit le régime étudié, elle s'est caractérisée par un accroissement des valeurs de l'insuline immédiatement après les repas. Dans le cas du repas du matin, cet accroissement précède de quelques minutes le début du repas et le pic postprandial est plus important que son homologue du soir (fig 5). Enfin, et exception faite pour le régime $\mathrm{LN}-\mathrm{HE}$, l'insulinémie tend à diminuer en période nocturne, cette baisse débutant tôt ( $20 \mathrm{~h}$ ) avec le régime LN-LE et en milieu de nuit $(0 h)$ avec les régimes $\mathrm{HN}$-LE et $\mathrm{HN}-\mathrm{HE}$ (fig 5 ).

\section{Hormone de croissance}

Par comparaison avec le régime $\mathrm{HN}-\mathrm{HE}$, la sous-alimentation énergétique et/ou azotée s'est accompagnée d'un accroissement $(P<$ $0,05)$ des teneurs plasmatiques en $\mathrm{GH}$ (tableau IV).

En ce qui concerne l'évolution cinétique de la $\mathrm{GH}$, et quel que soit le régime étudié, elle s'est caractérisée par une non variation ou une chute des concentrations de la $\mathrm{GH}$ après le repas (fig 6). Ensuite, 2 à $3 \mathrm{~h}$ plus tard, les concentrations de la $\mathrm{GH}$ ten- 

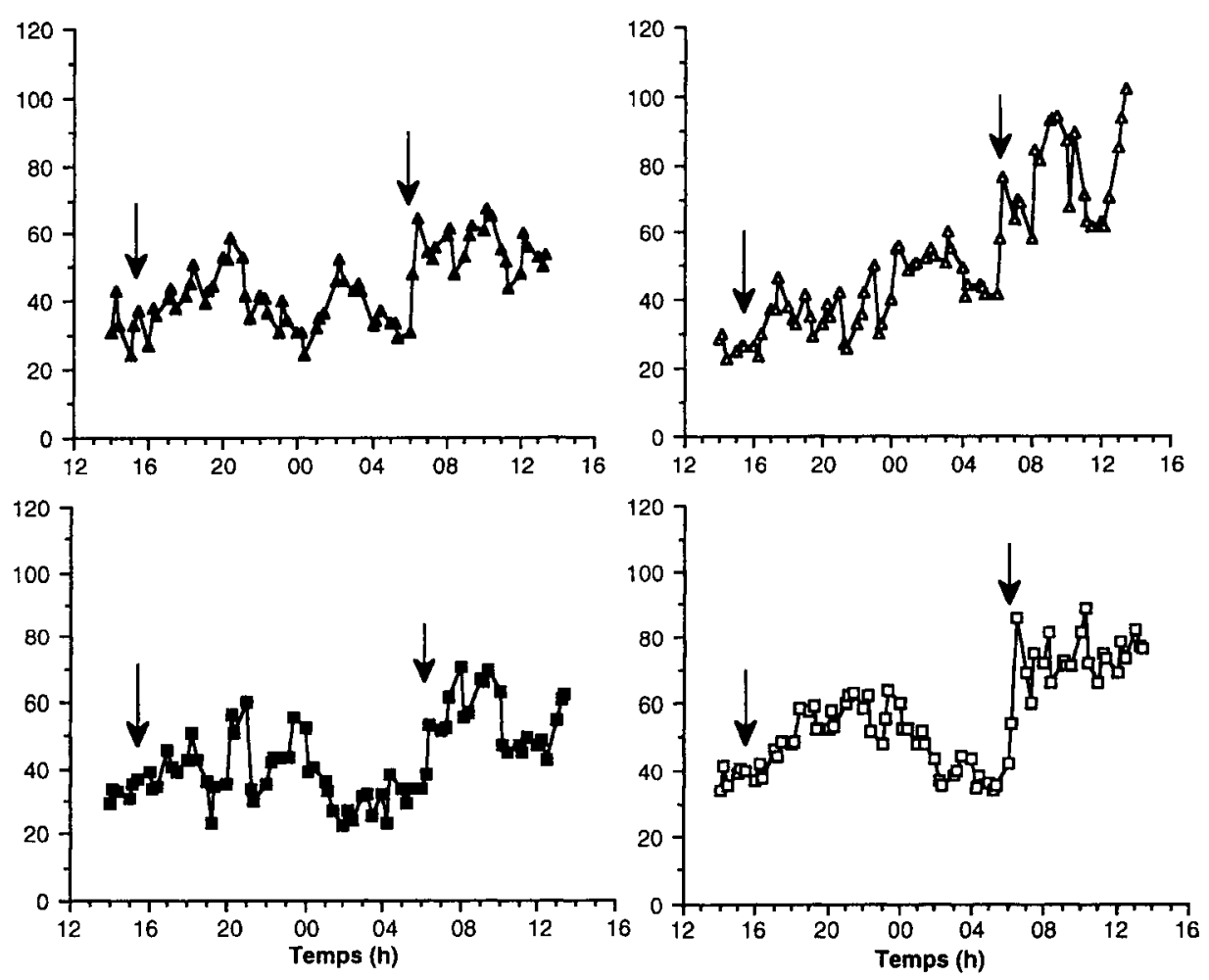

Fig 5. Évolution cinétique de l'insulinémie $(\mu \mathrm{U} / \mathrm{ml})$. Les flèches indiquent le moment des 2

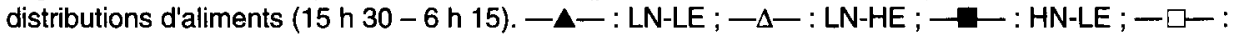
HN-HE.

dent à croître, cet accroissement s'étalant sur une longue période avec le régime $H N$ LE. Enfin, et exception faite du seul régime $\mathrm{HN}-\mathrm{HE}$, une nouvelle tendance à l'accroissement est observée pendant la période nocturne (fig 6).

L'analyse fine du profil journalier de la $\mathrm{GH}$ a abouti aux observations suivantes :

- quel que soit le niveau des apports azotés, une diminution du niveau énergétique de la ration s'est traduite par une élévation $(P<0,05)$ du nombre des pics de la $\mathrm{GH}$ et une diminution $(P<0,05)$ de l'intervalle qui les sépare (tableau $V)$;

- quel que soit le niveau énergétique, une diminution des apports azotés s'est traduite par une élévation de l'amplitude des pics de la $\mathrm{GH}$, significative $(P<0,05)$ à niveau énergétique haut (LN-HE) (tableau $V$ ) ;

- seul le régime LN-HE a différé $(P<0,05)$ des autres par sa plus grande surface sous les pics de la GH (tableau V).

\section{Excrétion urinaire de la 3-méthylhistidine}

Quel que soit le niveau des apports azotés, une diminution de la concentration énergétique de la ration s'est traduite par une augmentation $(P<0,05)$ de la quantité de la 3-MeHi excrétée par $24 \mathrm{~h}$ (tableau IV). 

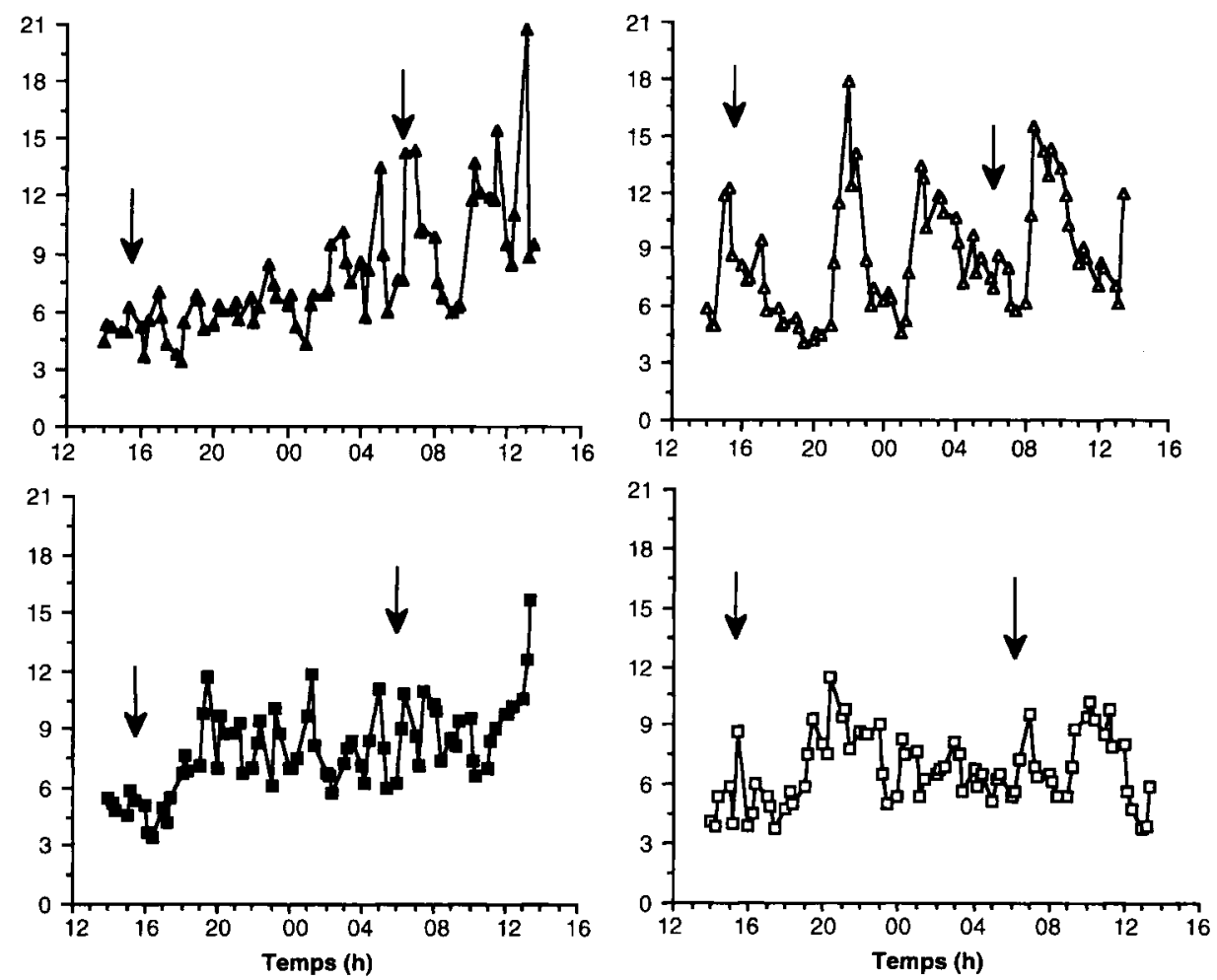

Fig 6. Évolution cinétique de l'hormone de croissance du plasma $(\mathrm{ng} / \mathrm{ml})$. Les flèches indiquent le moment des 2 distributions d'aliments $(15 \mathrm{~h} 30-6 \mathrm{~h} 15)$. $-\Delta-:$ LN-LE ; $-\Delta-:$ LN-HE ; HN-LE ; - - : HN-HE.

Tableau V. Analyse du profil moyen de l'hormone de croissance.

\begin{tabular}{lccccc} 
Régimes & LN-LE & LN-HE & $H N-L E$ & $H N-H E$ & ETM* \\
\hline Nombre des pics & $11^{\mathrm{a}}$ & $9^{\mathrm{ab}}$ & $10^{\mathrm{a}}$ & $8^{\mathrm{b}}$ & 0,4 \\
Amplitude des pics $(\mathrm{ng} / \mathrm{ml})$ & $8^{\mathrm{ab}}$ & $10^{\mathrm{a}}$ & $7^{\mathrm{ab}}$ & $6^{\mathrm{b}}$ & 0,3 \\
Intervalle entre les pics (min) & $133^{\mathrm{a}}$ & $163^{\mathrm{ab}}$ & $131^{\mathrm{a}}$ & $191^{\mathrm{b}}$ & 14 \\
Surface sous les pics (ng.min/ml) & $374^{\mathrm{a}}$ & $538^{\mathrm{b}}$ & $354^{\mathrm{a}}$ & $339^{\mathrm{a}}$ & 24 \\
\hline
\end{tabular}

* Écart type de la moyenne. a, b : les moyennes dans la même ligne qui n'ont pas une lettre commune en indice sont différentes statistiquement $(P<0,05) ; n=4$. 

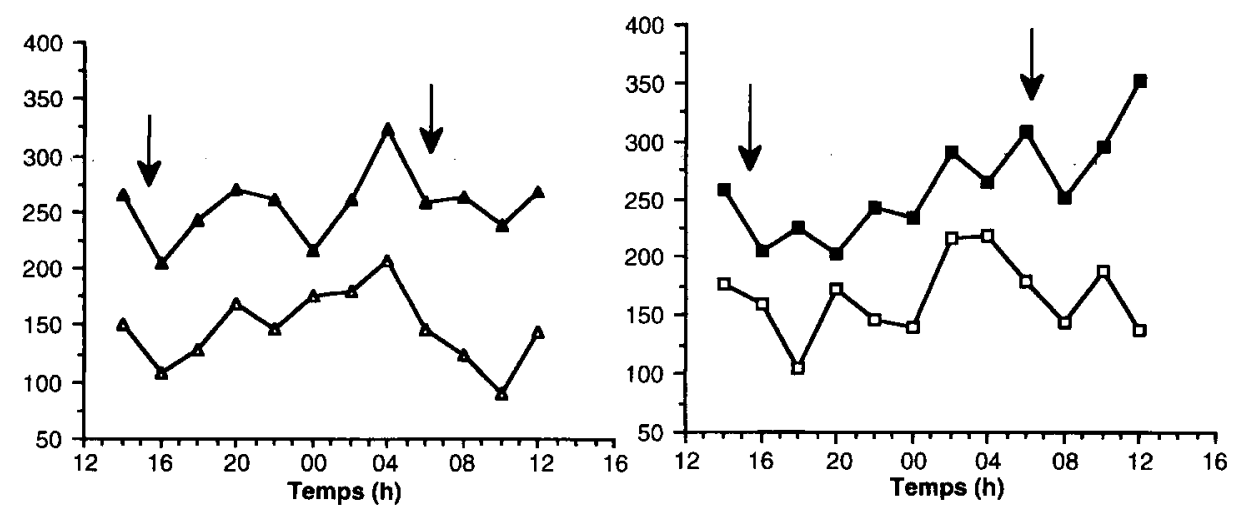

Fig 7. Évolution cinétique de l'excrétion urinaire de la 3-méthylhistidine ( $\mu$ moles). Chaque point représente la quantité moyenne de 3-méthylhistidine excrétée après $2 \mathrm{~h}$ de récolte continue d'urine el est centré sur la fin de cette période. Les flèches indiquent le moment des 2 distributions d'aliments (15 h $30-6$ h 15). $-\Delta-$ : LN-LE ; $-\Delta-=$ LN-HE ; $-\longrightarrow:$ HN-LE ; - $\square-:$ HN-HE.

L'évolution cinétique de ce paramètre s'est caractérisée par une diminution de l'excrétion urinaire de la 3-MeHi après les repas, surtout avec les 2 régimes excédentaires en énergie (LN-HE après le repas du matin et HN-HE après les 2 repas). Ensuite ce paramètre a eu tendance à croître pendant la période nocturne $(23 \mathrm{~h}$ à $4 \mathrm{~h}$ ), surtout avec le régime HN-LE (de $20 \mathrm{~h}$ jusqu'au repas du matin) (fig 7).

\section{DISCUSSION}

\section{Les niveaux moyens}

Par comparaison avec le régime excédentaire en azote et en énergie (HN-HE), la sous-alimentation s'est systématiquement caractérisée par une diminution des teneurs en AGV totaux du rumen, un relèvement des niveaux de la Gly et de la $\mathrm{GH}$ du plasma, et un maintien de la glycémie. En outre, la sous-alimentation azotée et énergétique (LN-LE) s'est accompagnée d'une réduction des concentrations plasmatiques en Ala, GIn et insuline ; la sous-alimenta- tion azotée (LN-HE), d'une élévation des niveaux de la sérinémie, d'une diminution de ceux de l'urémie et d'un maintien des niveaux de l'insulinémie ; la sous-alimentation énergétique (HN-LE), d'une élévation des concentrations plasmatiques en Ala et en Ser et d'une diminution de celles de l'insuline.

Des résultats similaires ont déjà été observés ailleurs. En effet, une diminution des teneurs en AGV totaux (Cecava et al, 1991 ; taurillons), de l'alaninémie, de la glutaminémie et de l'urémie (Champredon et al, 1977 ; bovins), ainsi qu'un relèvement des concentrations plasmatiques en Gly et en Ser (Grizard et al, 1979 ; brebis) ont été rapportés en période de sous-alimentation. De même, la diminution des niveaux de l'insulinémie, le relèvement de ceux de la GH et le maintien de la glycémie sont en accord avec les observations faites chez les Bovins sous-alimentés (Peters, 1986 ; Bocquier et al, 1992) ou à jeun (Ndibualonji et Godeau, 1992).

Chez le Ruminant bien nourri (régime $\mathrm{HN}-\mathrm{HE}$ ), les AGV produits dans le rumen, principalement l'acétate, constituent la principale source d'énergie tandis que le pro- 
pionate est le principal substrat glucoformateur (Bergman, 1990). En revanche lorsque l'animal est sous-alimenté en azote et/ou en énergie, ceci n'est plus le cas car l'activité et la prolifération de la population microbienne du rumen sont limitées ; il en résulte une diminution de la vitesse des fermentations (Leng, 1970). Par conséquent, il est possible que, comme rapporté par Lomax et Baird (1983), les vaches du présent essai aient répondu à la diminution des teneurs en AGV du rumen, consécutive à la sous-alimentation, par une mobilisation des protéines musculaires, cette dernière étant favorisée par un nouvel équilibre endocrinien (concentrations plus élevées en GH et plus faibles en insuline) (tableau IV). Ces adaptations métaboliques et hormonales devraient permettre aux animaux, d'une part, de satisfaire leurs besoins énergétiques via l'oxydation des AA mobilisés et, d'autre part, de maintenir leur glycémie via la néoglucogenèse acide aminé-dépendante. Ceci rend compte de la diminution des niveaux de l'alaninémie et de la glutaminémie enregistrée avec le régime $L N-L E$, ces 2 AA étant les principaux AA glucoformateurs chez la vache (Lomax et Baird, 1983 ; Ndibualonji et Godeau, 1993).

En réalité, la mobilisation des protéines musculaires était plus marquée avec les 2 régimes déficitaires en apports énergétiques (LN-LE et HN-LE) qui se sont accompagnés d'une diminution significative des concentrations circulantes en insuline et d'un accroissement significatif de la quantité de la 3-MeHi excrétée dans les urines par $24 \mathrm{~h}$. Rappelons que cette dernière est un index fiable du catabolisme des protéines myofibrillaires chez les Bovins puisque, chez ces animaux, la 3-MeHi n'est pas retenue après la dégradation protéique mais est quantitativement excrétée dans les urines (Harris et Milne, 1981). Ces observations suggèrent donc que le niveau énergétique de la ration est le facteur déterminant pour la mobilisation des protéines musculaires.
Cette hypothèse est renforcée par les travaux de Boisclair et al (1988, cités par Lobley, 1990) : chez des taurillons sous-alimentés énergétiquement, le passage d'une ration couvrant $180 \%$ des besoins d'entretien à une autre ne les couvrant qu'à $60 \%$ a été suivi d'une diminution de la synthèse protéique dans les muscles postérieurs (de 5,2 à $2,6 \mathrm{~g} / \mathrm{h}$ ).

Néanmoins, à l'instar de la sous-alimentation énergétique, la sous-alimentation azotée était accompagnée d'une élévation significative des concentrations plasmatiques en Gly et en GH. La Gly est parmi les AA les plus abondants dans les protéines musculaires chez la vache laitière et un relèvement de sa concentration plasmatique ainsi que celle de la Ser (régimes LN-HE et HNLE) suggère également, comme le propose Bergen (1979), une prépondérance du catabolisme des protéines de réserve. Quant à l'élévation des valeurs de l'alaninémie enregistrée avec le régime HN-LE, elle semble cohérente avec le rôle proposé de cet $A A$ dans le transport du carbone et de l'azote du muscle au foie (Heitmann et Bergman, 1980). De même, le niveau journalier moyen plus élevé de la $\mathrm{GH}$, consécutive à l'augmentation du nombre des pics (régimes $L N$ LE et LN-HE) ou de leur amplitude (régime LN-HE), est cohérent avec le rôle important joué par cette hormone dans les adaptations métaboliques relatives à la répartition et la fourniture des nutriments nécessaires au métabolisme énergétique et à la synthèse du glucose chez la vache (McAtee et Trenkle, 1971).

Certains travaux menés chez les Bovins en croissance (Peters, 1986) ou en lactation (Cisse et al, 1991) et chez le mouton (Parkes et Bassett, 1985) ont montré que l'influence de l'insuline sur le métabolisme du glucose est diminuée en présence d'un excès d'hormone de croissance (effet diabétogène). Pareil effet semble s'être manifesté chez nos vaches alimentées avec le régime déficitaire en azote (LN-HE) : la plus 
grande valeur de la GH du plasma, mais aussi un maintien des valeurs physiologiques de la glycémie malgré une insulinémie élevée ont été observés avec ce régime (tableau IV). Ces interactions hormonales sont totalement inconnues en ce qui concerne la régulation du métabolisme protéique (Grizard et al, 1988). Toutefois, bien que l'excrétion urinaire de la 3-MeHi n'ait pas été influencée, le régime LN-HE s'était également accompagné d'une élévation significative des concentrations plasmatiques en Gly et en Ser, suggérant que les taux circulants élevés en GH avaient bien induit une diminution de la sensibilité des tissus périphériques à l'action inhibitrice de l'insuline sur la mobilisation des AA musculaires.

Par ailleurs, le niveau journalier de l'urémie n'a été affecté à la baisse que par la sous-alimentation azotée (LN-HE vs HN$\mathrm{HE}$ ) alors qu'à niveau azoté similaire une diminution de la concentration énergétique de la ration a eu tendance à augmenter les valeurs de l'urémie. Une telle chute pourrait, comme le suggère Smith (1989), être la conséquence du recyclage de l'urée vers le tube digestif, ainsi que l'indique l'accroissement de l'apport d'azote endogène détecté au niveau duodénal lorsque les animaux étaient sous-alimentés en azote. Selon Huntington (1989), on peut supposer qu'un tel recyclage s'est produit vers le rumen plutôt que vers le tractus post-ruminal ; ce qui devrait permettre une bonne utilisation de l'azote alimentaire apporté en quantité limitée. Ces observations sont supportées par la diminution $(P<0,05)$ de l'excrétion urinaire de l'urée et des niveaux journaliers moyens de l'ammoniac du rumen enregistrée avec le régime $L N-H E$ au cours du présent essai (résultats non présentés). Cependant, la chute du niveau ammoniacal indique probablement une utilisation microbienne maximale de l'ammoniac en liaison avec l'énergie apportée par le régime. En effet, chez un Ruminant qui reçoit une ration carencée en azote et excédentaire en énergie, la synthèse des protéines et des AA microbiens à partir de l'azote uréique est favorisée (Houpt, 1970).

\section{Les évolutions nycthémérales}

Si nos résultats ont confirmé les variations journalières bien connues des concentrations des AGV du rumen et de certains métabolites et hormones du plasma, ils ont également montré l'influence non seulement du moment du repas, mais aussi du niveau azoté et énergétique de la ration sur l'importance de ces variations.

Comme Kunz et al (1985), nous avons observé une diminution des concentrations plasmatiques en $A A$ entre 3 et $6 \mathrm{~h}$ après le repas, cette diminution étant beaucoup plus importante avec les 2 régimes excédentaires en azote. Ceci peut s'expliquer par une réduction de la dégradation protéique dans les muscles comme l'indiquent l'élévation des taux circulants en insuline et la diminution de l'excrétion urinaire de la 3 $\mathrm{MeHi}$ en période postprandiale. Toutefois, cette diminution de l'excrétion urinaire de la 3-MeHi était également beaucoup plus importante avec les régimes $\mathrm{HN}$-LE et $\mathrm{HN}$ $\mathrm{HE}$, ce qui, ajouté au long étalement du pic postprandial des AGV du rumen enregistré avec ces 2 régimes, suggère une épargne importante des AA dans les protéines musculaires au moment où la disponibilité en AGV du rumen est maximale. La plus longue durée d'ingestion des repas (soir : $\mathrm{HN}-\mathrm{LE}$ et HN-HE, et matin : HN-HE) observée avec les 2 derniers régimes soutient cette dernière hypothèse. Par ailleurs, Bassett (1974a) a observé chez le mouton une corrélation positive et significative entre les teneurs en AGV du rumen et l'insulinémie en période postprandiale et, dans notre étude, ces 2 paramètres ont augmenté après le repas. Ces observations sont corroborées par le fait que l'injection d'insuline chez le 
mouton n'empêche pas l'incorporation du propionate marqué au ${ }^{14} \mathrm{C}$ dans le glucose plasmatique, mais réduit de 30 à $50 \%$ la néoglucogenèse à partir des $\mathrm{AA}$, du lactate et du glycérol (Brockman, 1990). Dès lors, on peut penser que, après le repas d'un Ruminant, le rôle de l'insuline est de favoriser la néoglucogenèse propionate-dépendante au détriment de la voie utilisant les autres précurseurs, ce qui permet d'épargner ceux-ci au moment où la contribution du propionate à la synthèse du glucose est maximale.

Le pic postprandial de l'insulinémie observé le matin précédait de quelques minutes le début du repas et était beaucoup plus important que son homologue du soir. S'il est bien établi chez le monogastrique que l'activité orosensorielle des aliments est responsable, par activation du nerf vague, d'une insulino-sécrétion précoce (Niijima, 1989), un mécanisme mettant en jeu le réflexe vagal a également été proposé chez le mouton (Bassett, 1974b) comme cause de la sécrétion précoce de l'insuline. Selon ce dernier auteur, l'élévation anticipée des concentrations circulantes en insuline joue un rôle métabolique important en préparant les tissus au flux des nutriments ; ceci permet de minimiser les perturbations de l'homéostasie liées à l'ingestion du repas.

La prépondérance du pic postprandial de l'insulinémie du matin sur celui du soir pourrait être due à la plus rapide vitesse d'ingestion du repas matinal. En effet, Bassett (1975) rapporte que l'ingestion rapide d'un aliment est responsable d'une libération rapide des hormones gastro-intestinales, sécrétine et cholécystokinine-pancréozymine, qui sont connues pour leur effet hyperinsulinémiant. Cependant, dans nos conditions expérimentales, seuls les 2 régimes excédentaires en azote se sont caractérisés par une élévation $(P<0,05$; tableau III) de la vitesse d'ingestion du repas matinal.
La diminution ou la non-variation des concentrations circulantes en $\mathrm{GH}$ après le repas rejoint les observations antérieures (Hove et Blom, 1973 ; Ndibualonji et Godeau, 1992) et serait due, selon Bassett (1974b), à un mécanisme réflexe lié à l'ingestion du repas. Mais la diminution pourrait aussi être expliquée par l'augmentation de la vitesse de sécrétion de la somatostatine qui est observée après le repas (Trenkle, 1978).

Comme Miettinen et Juvonen (1990), nous avons observé un accroissement soutenu des valeurs de l'urémie entre minuit et $9 \mathrm{~h}$ du matin environ, cette évolution étant mieux marquée dans notre étude avec les 2 régimes déficitaires en apports azotés. Un tel accroissement peut s'expliquer par un catabolisme accru des AA comme le suggère la réduction des concentrations plasmatiques en Ala (régime LN-LE), en Gln, Gly et Ser (régime HN-LE) pendant la période nocturne. En outre, et à l'instar des niveaux journaliers moyens enregistrés lors de la sous-alimentation, nous avons observé pendant la période nocturne une tendance à la diminution des teneurs en AGV totaux du rumen et en insuline du plasma, et une augmentation de la quantité de la $3-\mathrm{MeHi}$ urinaire excrétée et des concentrations circulantes en GH (vaches sous-alimentées seulement) et en glucose. Ces observations montrent que pendant la longue période interprandiale de nuit (14 h) la disponibilité en propionate glucoformateur et en substrats énergétiques (AGV) était limitante, les animaux réagissant exactement comme en période de sous-alimentation en mobilisant les réserves protéiques.

Cependant, et contrairement aux autres régimes, les valeurs nocturnes de la $\mathrm{GH}$ ont eu plutôt tendance à baisser avec le régime HN-HE. Ceci peut être dû au niveau d'ingestion élevé $(7,3 \mathrm{~kg} / \mathrm{j})$ qui a caractérisé ce régime. Nous avons en effet observé avec ce dernier régime les plus longues durées d'ingestion des repas, surtout celui du soir, 
ce qui pourrait traduire un ralentissement du transit et, partant, un allongement de la période d'absorption des nutriments. Ceci devrait théoriquement limiter la mobilisation des réserves endogènes pendant la période nocturne. De même, nous avons observé en période nocturne avec le régime $\mathrm{LN}-\mathrm{HE}$ un accroissement simultané des valeurs du glucose et de la $\mathrm{GH}$ en présence des taux circulants élevés en insuline, ce qui soutient l'hypothèse d'un effet diabétogène de la GH déjà proposé avec ce même régime.

En conclusion, la présente étude des niveaux moyens de certains métabolites et hormones impliqués dans l'homéostasie glucidique suggère que la vache tarie s'adapte à la sous-alimentation en mobilisant ses réserves protéiques. Cependant, dans les conditions expérimentales du présent essai, la mobilisation protéique n'était manifeste que lors de la sous-alimentation énergétique comme l'indiquent la réduction des valeurs de l'insulinémie et l'accroissement de la quantité de la 3-MeHi excrétée par $24 \mathrm{~h}$. En outre, la sous-alimentation s'est systématiquement accompagnée d'une élévation significative des taux circulants en $\mathrm{GH}$; ceci suggère que l'élévation des valeurs en $\mathrm{GH}$ pourrait être un des mécanismes impliqués dans la mobilisation des protéines endogènes lorsque la disponibilité en nutriment devient limitante. Par ailleurs, l'étude de l'évolution nycthémérale a révélé l'influence du moment du repas et du niveau des apports azotés et énergétiques de la ration sur les variations des paramètres étudiés.

\section{REMERCIEMENTS}

Les auteurs tiennent à remercier le Dr M Diez pour le traitement statistique des données. Nous remercions également le Dr P Debue, M JM Timmermans, M P Dumont et Mine A Huybens pour leur contribution aux prélèvements et aux analyses des échantillons de plasma. Ce travail a été supporté en partie par l'Institut pour l'encouragement de la recherche scientifique dans l'in- dustrie et dans l'agriculture (IRSIA, rue de Crayer, 6, B-1050 Bruxelles, Belgique).

\section{RÉFÉRENCES}

Andrieu J, Demarquilly C, Sauvant D (1988) Tables de la valeur nutritive des aliments. In: Alimentation des Bovins, Ovins et Caprins (R Jarrige, ed), INRA Publ, Paris, 351-443

Bassett JM (1974a) Diurnal patterns of plasma insulin, growth hormone, corticosteroid, and metabolite concentrations in fed and fasted sheep. Austr J Biol Sci 27, 167-181

Bassett JM (1974b) Early changes in plasma insulin and growth hormone levels after feeding in lambs and adult sheep. Aust J Biol Sci 27, 157-166

Bassett JM (1975) Dietary and gastro-intestinal control of hormones regulating carbohydrate metabolism in ruminant. In : Digestion and Metabolism in the Ruminant (IW McDonald, ACI Warner, eds), The Univ New England Publishing Unit, Australia, 165-179

Bergen WG (1979) Free amino acids in blood of ruminants. Physiological and nutritional regulation. $J$ Anim Sci 49 , 1577-1589

Bergman EN (1990) Energy contributions of volatile fatty acids from the gastrointestinal tract in various species. Physiol Rev 70, 567-589

Blum JW, Jans F, Moses W et al (1985) Twenty-four hour pattern of blood hormone and metabolic concentrations in high-yielding dairy cows: effects of feeding low or high amounts of starch, or crystalline fat. Zb/ Vet Med A32, 401-418

Bocquier F, Sala AM, Chilliard Y (1992) Effect of energy intake and bST treatment on plasma hormones and metabolites in the dry non-pregnant adult cows. J Dairy Sci 75 (Suppl 1), 235 (Abst)

Brockman RP (1990) Effect of insulin on the utilization of propionate in gluconeogenesis in sheep. $\mathrm{Br} J$ Nutr 64 , 95-101

Cecava MJ, Merchen NR, Berger LL, Mackie RI, Fahey Jr GL (1991) Effects of dietary energy level and protein source on nutrient digestion and ruminal nitrogen metabolism in steers. J Anim Sci 69, 2230-2243

Champredon C, Rémond B, Pion R (1977) Influence d'une sous-alimentation énergétique et azotée sur l'aminoacidémie libre de vaches laitières en début de lactation. CA Soc Biol 171, 60-66

Cisse M, Chilliard Y, Coxam V, Davicco MJ, Rémond $B$ (1991) Slow release of somatotropin in dairy heifers and cows fed 2 levels of energy concentrate. 2 . Plasma hormones and metabolites. J Dairy Sci 74, 1382-1394

Clement C, Jans F, Blum J (1991) Hormones and metabolites in lactating dairy cows fed insufficient amounts of protein. J Anim Physiol Anim Nutr 65, 244-253 
Cox DR (1958) The interpretation of the effects of nonadditivity in the Latin square. Biometrika 45, 69-73

Dehareng D, Godeau JM (1991) The durations of masticating activities and the feed energetic utilization of Friesian lactating cows an maize silage-based rations. J Anim Physiol Anim Nutr 65, 194-205

Duncan DB (1955) Multiple range and multiple $F$-tests. Biometrics 11, 1-42

Grizard J, Tissier M, Champredon C, Prugnaud J, Pion $R$ (1979) Variations des teneurs sanguins en acides aminés libres, urée et glucose chez la brebis en fin de gestation et début lactation. Influence de l'état nutritionnel en fin de gestation. Ann Biol Anim Bioch Biophys 19, 55-71

Grizard J, Attaix D, Champredon C, Bonin D, Arnal M (1988) Orientations et coordination hormonale du métabolisme protéique chez les Ruminants. Reprod Nutr Dev 28, 19-37

Harris $\mathrm{Cl}$, Milne $\mathrm{G}$ (1981) The urinary excretion of $\mathrm{N}^{\mathrm{r}}$. methyl histidine by cattle: validation as an index of muscle protein breakdown. Br J Nutr 45, 411-422

Heitmann RN, Bergman EN (1980) Integration of amino acid metabolism in sheep. Am J Physiol 239, 248 254

Houpt R (1970) Transfer of urea and ammonia to the rumen. In : Physiology of Digestion and Metabolism in theRuminant (AT Phillipson, ed), Oriel Press Limited, New Castle Upon Tyne, Royaume-Uni, 119-131

Hove K, Blom AK (1973) Plasma insulin and growth hormone in dairy cows: diurnal variation and relation to food intake and plasma sugar and acetoacetate levels. Acta Endocr 73, 289-303

Huntington GB (1989) Hepatic urea synthesis and site and rate of urea removal from blood of beef steers fed alfalfa hay or high concentrate diet. Can J Anim Sci 69, 215-223

Kunz PL, Blum JW, Hart IC, Bickel H, Landis J (1985) Effects of differents energy intakes before and after calving on food intake, performance and blood hormones and metabolites in dairy cows. Anim Prod $1985,40,219-231$

Ladewig J, Stribrny K (1988) A simplified method for stress free continuous blood collection in large animals. Lab Anim Sci 38, 333-334

Leng RA (1970) Fermentation and production of volatile fatty acids in the rumen. In : Physiology of Digestion and Metabolism in the Ruminant (AT Phillipson, ed), Oriel Press Limited, Newcastle upon Tyne, UK, 407-421

Lobley GE (1990) Energy metabolism reactions in ruminant muscle: responses to age, nutrition and hormonal status. Review. Reprod Nutr Dev 30, 13-34
Lomax MA, Baird GD (1983) Blood flow and nutrient exchange accoss the liver and gut of the dairy cow. Br J Nutr 49, 481-496

McAtee JW, Trenkle A (1971) Effect of feeding, fasting and infusion of energy substrates on plasma growth hormone levels in cattle. J Anim Sci 33, 612-616

Miettinen PVA, Juvonen RO (1990) Diurnal variations of serum and milk urea levels in dairy cows. Acta Agric Scand 40, 289-296

Ndibualonji BB, Godeau JM (1992) Kinetic evolution of plasma amino acids, glucose and hormones in fed and short-term fasted Friesian cows. Med Fac Landbouww Univ Gen 57, 1985-1991

Ndibualonji BB, Godeau JM (1993) La néoglucogenèse et les acides aminés chez les Ruminants ; revue. Ann Méd Vét 537-554

Ndibualonji BB, Dehareng D, Debue P, Godeau JM (1992) Détermination des acides aminés libres du plasma par HPLC et étude des effets du jeûne sur l'aminoacidémie libre chez la vache Frisonne tarie. Ann Méd Vét 136, 413-422

Niijima $A$ (1989) Les mécanismes nerveux de la régulation de la glycémie. Arch Inter Physiol Bioch 97, A37-A49

Otchere EO, McGilliard AD, Young JW (1974) Quantitation of $\alpha$-linked glucose polymers passing to the small intestine in cattle. J Dairy Sci 57, 1189-1195

Parkes MJ, Bassett JM (1985) Antagonism by growth hormone of insulin action in fetal sheep. $J$ Endocr $105,379-382$

Peters JP (1986) Consequences of accelerated gain and growth hormone administration for lipid metabolism in growing beef steers. J Nutr 116, 2490-2503

Schmidt FH (1961) Die enzymatische bestimmung von glucose und fructose nebeneinander. Klin Wschr 39, 1244-1247

Smith RH (1989) Nitrogen metabolism in the ruminant stomach. In : Protein Metabolism in Farm Animals (HD Bock, BO Eggum, AG Low, O Simon, T Zebrowska, eds), Oxford Sci Publ-Deutscher Landwirtschaftsverlag, Berlin, Allemagne, 165-203

Taylor PL (1987) Munro. Hormones-Pulses. Zaristow Software Pub, UK

Trenkle A (1978) Relation of hormonal variations to nutritional studies and metabolim of ruminants. $J$ Dainy $S c i$ $61,281-293$

Van Eenaeme C, Bienfait JM, Lambot O (1965) La détermination quantitative des acides gras volatils dans le liquide du rumen par chromatographie en phase gazeuse. Ann Méd Vét 109, 569-584

Vérité R, Peyraud JL (1988) Nutrition azotée. In : Alimentation des Bovin.s, Ovins et Caprins (R Jarrige éd), INRA Publ, Paris, 75-83 